\title{
Positive Well-Being and Work-Life Balance among UK Railway Staff
}

\author{
Jialin Fan, Andrew P. Smith \\ Centre for Occupational and Health Psychology, School of Psychology, Cardiff University, Cardiff, UK \\ Email: FanJ12@Cardiff.ac.uk, SmithAP@Cardiff.ac.uk
}

How to cite this paper: Fan, J.L. and Smith, A.P. (2017) Positive Well-Being and Work-Life Balance among UK Railway Staff. Open Journal of Social Sciences, 5, 1-6. https://doi.org/10.4236/jss.2017.56001

Received: April 12, 2017

Accepted: June 6, 2017

Published: June 9, 2017

\begin{abstract}
Failure to manage the well-being and work-life balance of railway workers may result in an increased risk to train safety and employees' health. This article reports the findings of a study that measured positive well-being and work-life balance, and identified the factors affecting these among UK railway staff. On the whole, staff who perceived high levels of control and support had a better work-life balance and an increased sense of well-being. A positive personality was associated with positive well-being both at work and outside of work.
\end{abstract}

\section{Keywords}

Well-Being, Work-life Balance, Subjective Well-being, Train Crew

\section{Introduction}

Railway workers usually work under a heavy workload and have irregular work hours. Due to the nature of the railway industry, the majority do shiftwork (e.g. early-morning shifts that start before 6:00 a.m. or night shifts that end after 4:00 a.m.), and they are often exposed to noise or fumes at work.These job characteristics may damage workers' personal well-being, either at work or outside work. Improving train staff's well-being not only benefits their personal health, but also reduces the risk of the train safety problems.

"Well-being" can be understood as how people feel, either in their personal life or at work, and how they evaluate their lives as a whole [1]. Earlier research on well-being has largely been focused on negative states, such as anxiety, depression and stress [2]. However, in later studies, positive well-being was also considered an important element of well-being as a whole. Positive well-being includes positive experiences and subjective judgements. It is commonly represented broadly by happiness and satisfaction [3]. Social support [4] and person- 
ality [5] have been found to play important roles in positive well-being.

Previous research on well-being at work has focused on job characteristics, such as job demands, and job support/control. Nonetheless, it is also important to measure individual characteristics, such as personality and healthy lifestyle. A model that accounts for both is the demands, resources, and individual effects (DRIVE) model [6], which was used in the present research. This model includes both job characteristics and individual characteristics that may influence well-being outcomes.

Positive well-being at work is predicted by a positive personality [7], and job support and control [8]. Negative job characteristics, such as high job demands and a poor working environment, are, in turn, associated with impaired well-being either at work or in family life, and with a negative work-life balance [9]. The negative work-life balance (also called work-life conflict) represents an incompatibility between work and personal life due to limited resources, such as time and energy. It has been associated with decreased well-being, including reduced job and life satisfaction, and decreased life happiness [10] [11].

To manage and improve their well-being, it is necessary to establish a profile of well-being among staff members working in the rail industry. This study aims to examine positive well-being and work-life balance, and to identify the risk factors that affect these, among UK railway staff. The purpose is also to build a picture of the relationship between positive well-being at work and positive well-being outside of work.

\section{Method}

\subsection{Ethical Approval}

This study has been reviewed and approved by the School of Psychology Research Ethics Committee at Cardiff University. It was carried out with the informed consent of the participants.

\subsection{Participants}

Participants were recruited from a train company in the UK, and 1067 of them completed the questionnaires $(\mathrm{N}=1067$, mean $( \pm \mathrm{SD})$ age $=44.25 \pm 10.763 \mathrm{yr}$.$) ,$ with a response rate of approximately $50 \%$. The participants carried out a range of jobs, mainly including conductors, drivers, station workers, engineers, administrator, managers, at-seat catering stewards and controllers.

\subsection{Materials}

Due to practical constraints, a short survey with single item questions was used in the occupational context because it was quick and easy to administer, and it posed minimal disruption to the workers. This survey ran from 27 April to 18 May 2015.

The well-being questionnaire used in the present study was the Smith Well-being Questionnaire (SWELL) [8]. The items in SWELL were derived from the Well-being Process Questionnaire (WPQ), a single-item scale. Previous re- 
searchers have confirmed the validity and reliability of such single-item well-being measures [8] [9] [12]. They allow for the identification of overall risk and well-being while saving time in comparison with multi-item measures.

The SWELL questionnaire consists of 26 single-item questions from the WPQ and takes about 15 minutes to complete. Most questions were on a 10-point scale, and the remainder were yes-no questions. The survey consisted of two sections based on the DRIVE model and WPQ. The first section measured respondents' personal details (e.g. age, gender and job role), individual characteristics, and work characteristics. Participants were asked to state to what extent they had a healthy lifestyle, and a positive personality. The questions about work characteristics included job demands, job control and support, working environment (levels of noise and fumes), and whether participants worked in shifts. The second section, which measured well-being outcomes, included positive well-being (i.e. job satisfaction, happiness at work, life satisfaction, and happiness outside work) and work-life balance.

\subsection{Procedure}

The questionnaire began by providing participants with information about the study, which was followed by an informed consent form. Participants were free to withdraw from the survey at any point. Also, they were told that they were free to not respond to those questions that they felt uncomfortable to answer. The participants then completed a paper questionnaire with 26 questions. Upon completion, the participants were debriefed about the survey.

\subsection{Statistical Analyses}

A few participants did not fully complete the questionnaire. Such incomplete questionnaires were kept in the data analysis. Descriptive analysis examined the frequency of responses. Then, the variables were dichotomised into high/low groups (usually by using the thresholds; e.g. above thresholds for high group). Logistic regressions were then performed to uncover which factors predicted positive well-being outcomes and work-life balance, and to test for possible interaction effects.

\section{Results}

\subsection{Descriptive Statistics}

The frequencies for each variable are shown in Table 1. Comparing across the variables, the sample had generally higher scores on control and support, and lower scores on exposure to noise, vibration and fumes. Nearly three-quarters (74.9\%) of the participants did shift work. In terms of well-being outcomes, the sample showed high satisfaction and happiness, both at work and outside work. The workers' work-life balance, however, was generally poor.

Very few of the participants rated their personality or health behaviours negatively (both had a threshold of 4). It may be because people are unable to judge 
Table 1. Descriptive statistics for each variable using the single-item measures.

\begin{tabular}{cccc}
\hline Variable & $\mathrm{N}^{a}$ & $\begin{array}{c}\text { Frequency Above } \\
\text { Threshold }\end{array}$ & \% Above Threshold \\
\hline Health Lifestyle & 1064 & 914 & $85.9 \%$ \\
Positive Personality & 1067 & 1000 & $93.7 \%$ \\
Job Demands & 1063 & 582 & $54.4 \%$ \\
Job Control and Support & 1063 & 941 & $88.5 \%$ \\
Exposure to Noise & 1065 & 499 & $46.9 \%$ \\
Exposure to Fumes & 1064 & 411 & $38.6 \%$ \\
Job Satisfaction & 1065 & 970 & $92.1 \%$ \\
Happiness at Work & 1064 & 985 & $92.6 \%$ \\
Life Satisfaction & 1067 & 977 & $91.6 \%$ \\
Happiness Outside Work & 1065 & 1009 & $94.7 \%$ \\
Negative Work-life Balance & 1062 & 532 & $50.1 \%$ \\
\hline
\end{tabular}

a. $\mathrm{N}$ is different for each because incomplete questionnaires were kept.

these characteristic in themselves. The two individual characteristic factors, therefore, were re-categorised by using median splits, instead of thresholds, in the following analysis.

\subsection{Dichotomised Variables}

The individual scores for the variables used in the following analysis were categorised as high or low using thresholds. For example, job satisfaction scores above the threshold were categorised as "high job satisfaction," while the others were categorised as "low job satisfaction." As noted earlier, a median split was used to recode both positive personality $(\mathrm{M}=8$, range $=1$ to 10$)$ and healthy lifestyle $(M=7$, range $=1$ to 10$)$ into high/low groups.

\subsection{Predictors of Outcomes}

Logistic regressions were run to uncover the predictors of high/low well-being and negative work-life balance outcomes. The results show that a positive personality and high levels of job support/control were significant predictors of positive well-being, including job satisfaction, life satisfaction, happiness at work, and happiness outside work. Other than these two predictors, high noise levels affected job satisfaction, doing shiftwork significantly reduced happiness at work, and a healthy lifestyle increased life satisfaction (all p’s $<0.05$ ).

The results also show that negative work-life balance was significantly predicted by most job characteristics examined, including high noise levels, doing shiftwork, high job demands, and low job support/control. Neither positive personality nor healthy lifestyle was shown to influence the negative work-life balance.

\section{Discussion and Conclusion}

The results of this study are in line with work of the previous researchers using 
other professional group samples, such as academics [13] and business outsourcing staff [8]. Most staff members surveyed were satisfied with their jobs and general life. Work-life balance, however, was generally poor. The results show that an optimistic personality and high levels of job support/control were the strongest predictors of job satisfaction, life satisfaction, happiness at work, and happiness outside work. A healthy lifestyle also increased life satisfaction. This confirms that positive characteristics predict positive well-being outcomes. In turn, negative job characteristics were damaging to positive well-being at work. High noise levels in the work environment resulted in lower job satisfaction, and doing shift work significantly reduced happiness at work.

Negative work-life balance can be found in both directions: the effect of work on life and the effect of life on work. In this study, it was significantly predicted by most of the job characteristics examined, including both lack of positive features (e.g. job support/control) and the presence of negative features (e.g. high job demands, shift work, high noise levels), but not by personal characteristics. This indicates that the job was interfering with life outside work. However, there was no evidence that life outside of work was interfering with the job as well.

The present study involved a short analysis using SWELL to measure positive well-being outcomes and to identify their key predictors in an occupational context. This methodology could easily be applied to further studies, such as measuring the effects of job or individual characteristics on negative well-being outcomes. Moreover, work-life balance was found to be predicted by multiple risk factors, which suggests that additive effects of the risk factors might exist. A combined-effects approach [14] could be adopted to examine these effects. In addition, in future studies, the negative work-life balance could be increased to two items; one that measures work's influence on life and another life's influence on work.

This study examined positive well-being and work-life balance, and identified the factors affecting these among UK railway staff. The results confirm that positive characteristics predict positive well-being both at work and outside of work, while work-life balance is predicted by both the absence of positive and presence of negative job characteristics.

\section{Acknowledgements}

We would like to acknowledge the contribution made by those who participated in the study, and we thank the participating rail company for their support and assistance

\section{References}

[1] Michaelson, J., Mahony, S., and Schifferes, J. (2012) Measuring Wellbeing: A Guide for Practitioners. New Economics Foundation, London.

[2] Parkinson, J. (2007) Review of Scales of Positive Mental Health Validated for Use with Adults in the UK: Technical Report. Health Scotland, a WHO Collaborating Centre for Health Promotion and Public Health Development, Edinburgh. 
[3] WHO (2012) Measurement of and Target-setting for Well-being: An Initiative by the WHO Regional Office for Europe. First Meeting of the Expert Group, Copenhagen.

[4] Chay, Y.W. (1993) Social Support, Individual Differences and Well-being: A Study of Small Business Entrepreneurs and Employees. Journal of Occupational and Organizational Psychology, 66(4), 285-302. https://doi.org/10.1111/j.2044-8325.1993.tb00540.x

[5] DeNeve, K.M. and Cooper, H. (1998) The Happy Personality: A Meta-Analysis of 137 Personality Traits and Subjective Well-being. Psychological Bulletin, 124(2), 197-229. https://doi.org/10.1037/0033-2909.124.2.197

[6] Mark, G.M. and Smith, A.P. (2008) Stress Models: A Review and Suggested New Direction. In: Houdmont, J. and Leka, S., Ed., Occupational Health Psychology: European Perspectives on Research, Education and Practice, EA-OHP Series, Nottingham University Press, 3, 111-144.

[7] Smith, A.P. and Smith, H.N. (2017a) A Short Questionnaire to Measure Wellbeing at Work (Short-SWELL) and to Examine the Interaction Between the Employee and Organisation. Proceedings of the Contemporary Ergonomics and Human Factors 2017, Staveton Estate, Daventry, Northamptonshire, 25-27 April 2017.

[8] Smith, A.P. and Smith, H.N. (2017b) An International Survey of the Wellbeing of Employees in the Business Process Outsourcing Industry. Psychology, 8, 160-167. https://doi.org/10.4236/psych.2017.81010

[9] Fan, J. and Smith, A.P. (2017) Workload, Fatigue and Performance in the Rail Industry. Proceedings of the H-Workload 2017: 1st International Symposium on Human Mental Workload: Models and Applications. Dublin, 28-30 June 2017.

[10] Allen, T.D., Herst, D.E., Bruck, C.S. and Sutton, M. (2000) Consequences Associated with Work-to-Family Conflict: A Review and Agenda for Future Research. Journal of Occupational Health Psychology, 5(2), 278-308. https://doi.org/10.1037/1076-8998.5.2.278

[11] Grant-Vallone, E.J. and Donaldson, S.I. (2001) Consequences of Work-Family Conflict on Employee Well-being over Time. Work \&Stress, 15(3), 214-226. https://doi.org/10.1080/02678370110066544

[12] Williams, G.M. and Smith, A.P. (2016) Using Single-Item Measures to Examine the Relationships between Work, Personality, and Well-Being in the Workplace. Psychology: Special Edition on Positive Psychology, 7, 753-767. https://doi.org/10.4236/psych.2016.76078

[13] Kinman, G. and Jones, F. (2008) A Life Beyond Work? Job Demands, Work-Life Balance, and Wellbeing in UK Academics. Journal of Human Behavior in the Social Environment, 17(1-2), 41-60. https://doi.org/10.1080/10911350802165478

[14] Smith, A., McNamara, R. and Wellens, B. (2004) Combined Effects of Occupational Health Hazards, Research Report 287, Prepared by Cardiff University for the Health and Safety Executive, Cardiff. 
Submit or recommend next manuscript to SCIRP and we will provide best service for you:

Accepting pre-submission inquiries through Email, Facebook, LinkedIn, Twitter, etc. A wide selection of journals (inclusive of 9 subjects, more than 200 journals)

Providing 24-hour high-quality service

User-friendly online submission system

Fair and swift peer-review system

Efficient typesetting and proofreading procedure

Display of the result of downloads and visits, as well as the number of cited articles Maximum dissemination of your research work

Submit your manuscript at: http://papersubmission.scirp.org/

Or contact jss@scirp.org 